\title{
CIÊNCIA, CULTURA E A TECNOLOGIA E A RESTAURAÇĀO MEIJI
}

Shozo Motoyama

A Restauração Meiji, ocorrida na segunda metade do século XIX, é um acontecimento ímpar na História. De fato, trata-se de um fenômeno histórico excepcional, quando se deu a transformação de um Japão atrasado economicamente para uma potência, num curto espaço de décadas. Simbólica, ela representa a implantação da modernidade na terra das cerejeiras. Por isso, tornou-se alvo de estudo dos historiadores japoneses preocupados com a identidade da sua nação no processo histórico moderno e contemporâneo marcado pela supremacia do ocidente. Por outro lado, recentemente, começou a interessar os estudiosos de outros países graças ao seu assombroso crescimento econômico observado atualmente. Como a maioria deles reconhece, a origem das características contemporâneas do país do Sol Nascente está na Restauração Meiji. Daí, a aura quase mítica que cerca o episódio. Portanto, não é de se estranhar que os próprios romancistas japoneses se debruçassem sobre o tema, criando heróis reais ou fictícios. É o caso do célebre romance de Ryotaro Shiba sobre Ryoma Sakamoto, um dos grandes nomes da Restauração, por exemplo.

Entretanto, apesar dessa profusão de escritos, talvez não seja exagero afirmar que muita coisa está para se fazer no campo de estudos sobre o assunto. Não que faltem bons trabalhos sobre o mesmo. Ninguém pode deixar de reconhecer méritos nas obras clássicas de Goro Hani, Kyoshi Inoue e outros. Porém, o tema, em si, é complexo. As diversas variáveis históricas se entrelaçam prolixa e confusamente não permitindo uma compreensão fácil ou linear. Em 
geral, um historiador de ofício desenreda apenas uma parte dessas variáveis, montando um quadro incompleto da trama geral. Esse quadro, comumente, é engendrado em função dos interesses existentes no momento histórico da realização da pesquisa. Por isso, já pode estar desfocado, no período seguinte. Nesse sentido, o tema se renova de geração a geração. Quanto mais complexo, mais duradouro como motivo de debates e estudos. Ao que tudo indica, pela sua atualidade e pela sua complexidade, a Restauração Meiji vai alimentar a literatura historiográfica ainda por muito tempo.

$O$ presente artigo não tem a intenção de fazer um balanço, mesmo que sintético, do assunto. Tal tarefa cabe muito mais a um historiador tarimbado, especialista do período em pauta no Japão. A idéia é tão-somente aventar uma hipótese sobre as razões do sucesso da Restauração Meiji, para posterior discussão e pesquisa. Ela consiste no ponto de vista de que esse sucesso se deveu a dois fatores. O primeiro é o fato dos responsáveis por essa transformação político-econômica da sociedade nipônica terem persistido com uma determinação férrea nos ideais da independência nacional. Resistiram indomavelmente às tentativas de vários matizes intentando submetê-los às autoridades forâneas. $\mathrm{O}$ segundo fator se refere a habilidade com que souberam associar o moderno com o tradicional para construírem as bases da sua nacionalidade. No caso, o moderno significa ciência e tecnologia (C\&T) e o tradicional a própria cultura japonesa com seus hábitos e manifestações artísticas. $\mathrm{O}$ objetivo deste trabalho é discutir esse segundo aspecto, ainda que preliminarmente.

Após um rápido e fecundo contato com os europeus no século XVI, o Japão se fechou praticamente em relação ao resto do mundo a partir de 1639 , por obra do xogunato de Tokugawa. Este, no entanto, no seu início (1603), havia estimulado o comércio exterior. Isso permitiu, nas primeiras décadas do século XVII, um ativo intercâmbio entre os japoneses e os seus vizinhos asiáticos. Em conseqüência, nessa época, os nipônicos estavam espalhados em vários lugares, mormente nas Filipinas, Tailândia, Camboja, Birmânia e outras localidades dos Mares do Sul. Essas regiōes serviram de palco para as ações dos japoneses como Nagamasa Yamada, legendário herói que chegou a ser rei de um pequeno país da Tailândia.

Todavia, em pouco tempo, essa política de estímulo ao intercâmbio com exterior, acabou. $O$ xogunato estava interessado antes de tudo, na estabilidade interna. $\mathrm{O}$ contato com os estrangeiros, de uma forma ou de outra, ameaçava o instável domínio dos Tokugawa. Os próprios japoneses foram proibidos de saírem das suas fronteiras. Pior. Os que estavam no território estrangeiros foram impedidos de retornarem. Por sua vez, o cristianismo, introduzido pelos jesuítas portugueses, estava trazendo problemas para o bakufiı (xogunato). Em rápida expansão, ele arregimentava adeptos de quase todas as camadas sociais, inclusi- 
ve entre os suseranos. Estava se tornando num poder paralelo, ameaçando a hegemonia do clã dos antigos senhores de Mikawa. Chegou a haver uma rebelião camponesa (1637), chefiada por Tokisada Shirô Amakusa, que sob a bandeira do cristianismo, resistiu durante muito tempo ao ataque das tropas leais ao xogunato. Isto, apesar da proibição do culto à religião cristã ter sido promulgada em 1587, no tempo de Hideyoshi Toyotomi, antes mesmo do estabelecimento do bakufu. Este, no entanto, recrudesceu a repressão contra os cristãos, disposto a acabar de vez com o cristianismo nas terras do Sol Nascente.

Contudo, esse isolamento não era total. Permitiu-se a entrada de holandeses e chineses num único porto, o de Nagasaki, para comerciar. Na verdade, os representantes do país das terras baixas tinham uma espécie de entreposto comercial naquele porto, na ilha de Dejima, onde ficavam confinados quase todo o tempo. Nos períodos iniciais, eles traziam seda para levar em troca ouro e prata. Ao que tudo indica, o lucro auferido pelos negociantes holandeses deveria ser vultoso, para eles se submeterem, durante mais de duzentos anos, às condições tão draconianas impostas pelas autoridades nipônicas. Para estas, entretanto, a permissão de se negociar com o estrangeiro somente num local, significava igualmente facilidade no controle das questões de importação e exportação, na cobrança dos impostos.

Esse isolamento durou mais de dois séculos. $\mathrm{O}$ clã dos Tokugawa obteve êxito nos seus intentos. Eles dominaram o país, quase sem contestação, durante todo esse período. Conseguiram impor um sistema de fiscalização permanente sobre os suseranos, impossibilitando-os de se sublevarem. Instituíram uma rígida hierarquia social constituída por bushi (samurais), agricultores e comerciantes. Além dessas classes, existiam a dos nobres e a dos senmin (plebe). Apesar da desigualdade social existente, da injusta distribuição de renda, da tirania dos costumes, esse período conhecido como o de Edo, beneficiando-se da relativa paz existente, propiciou um crescimento marcante das cidades, um progresso visível no comércio e um desenvolvimento palpável nas artes, nas técnicas e nos estudos.

As técnicas foram aperfeiçoadas nas lides agrícolas ou urbanas. Grandes obras de irrigação e de barragens dos rios, como aquelas feitas no. Tonegawa, são igualmente desse período. Melhorava-se o sistema de adubação, utilizavam-se arados puxados por bois, aperfeiçoavam-se aparelhos de descaroçamento e outros. Com isso, verificou-se uma produção abundante e diversificada de algodão, batata-doce, cana-de-açúcar, inhame, fumo, milho, abóbora, ervilha, cenoura, espinafre etc. $\mathrm{Na}$ área de manufatura também se observou uma evolução notável. Dessa forma, alguns tecidos se tornaram famosos como o Nishijin-ori de Kyoto, assim como o tingimento do tipo Yuzen-zome ou do Arimatsu-Shibori. Também os progressos são visíveis na cerâmica e nos objetos trabalhados com charão. Houve melhorias igualmente na fabricação de papel e nos processos de fermentação. Tornaram-se célebres os saquês de Itami e Nada e o shoyu de Noda. Nos transportes, os avanços foram na área de navegação, tanto marítima como fluvial. 
Não obstante essa evolução técnica, havia pouca possibilidade para o desenvolvimento da indústria propriamente dita. Na verdade, a economia nipônica girava em torno da agricultura, mormente do arroz. Os comerciantes se enriqueciam na compra e venda desse e de outros produtos agrícolas. Intermediavam do mesmo modo a produção artesanal. Exerciam atividade financeira tendo geralmente como clientes os samurais. No entanto, raramente, os comerciantes se aventuravam, eles mesmos, serem produtores. Os capitais acumulados, dessa forma, dificilmente eram investidos na produção propriamente dita. Além do mais, os negociantes japoneses, apesar de sua força, não estavam interessados em colocar em xeque a hegemonia dos samurais e do xogunato. Satisfeitos com a sua riqueza e posição, defendiam, de certo modo, a estrutura social estabelecida.

No período de Edo, a preocupação pela educação era grande. Os samurais tinham um longo e duro aprendizado para poderem exercer as suas funções. O próprio bakufu estimulava os estudos, sobretudo, aqueles relacionados com o confucionismo. O primeiro xogum, Yeyasu, contratou Razan Hayashi para a propagação da doutrina de Confúcio entre os seus subordinados. A partir de então, durante todo o domínio dos Tokugawa, a familia Hayashi recebeu a proteção do xogunato. Outro caso marcante foi o de Hakuseki Arai, um afamado estudioso do confucionismo, que exerceu cargos importantes no bakufu, no primeiro quarto do século XVIII. Por sua vez, interessados em se elevar culturalmente, os comerciantes se instruíam numa espécie de escola particular chamada terako-ya. Haviam também professores especializados para ensinar às meninas costura, cerimônia do chá, ikebana e música.

Como se pode ver, havia uma atividade bastante dinâmica no campo de estudos. Contudo, se comparado com que acontecia no Ocidente, na mesma época, nota-se uma ausência fundamental. Praticamente, não existe ciência. Ao contrário da Europa, que conhecera a revolução científica no século XVII, no Japão não havia muito interesse em aprofundar o conhecimento sobre a natureza propriamente dita. Os assuntos em pauta eram de caráter moral ou ético. Obviamente, não fora por acaso que o governo de xogum privilegiara o confucionismo. Este dava as bases filosóficas para justificar a existência da hierarquia de classes. Nesse sentido, não se poderia esperar dcle diretrizes na direção de um dinamismo social ou da modernidade. Ora, esta estava justamente no reconhecimento de que o saber, mormente aquele relacionado com o conhecimento da natureza, é poder, como bem afirmava Francis Bacon, o arauto da civilização industrial. Foi a falta de percepção desse fato essencial a razão da ciência não ter se desenvolvido na terra dos samurais. Explica, igualmente, por que a matemática tão bem iniciada no século XVII, com o cálculo diferencial e integral de Takakazu Seki, acabou-se estiolando numa espécie de jogo de quebra-cabeças.

No campo da cultura literária e artística, o período foi inovador. A ascensão econômica da classe dos comerciantes permitiu o surgimento de uma cultura popular centrada na vida urbana e cotidiana. No fim do século XVII, 
surgiu uma literatura de ficção tendo como tema os assuntos do dia-a-dia, conhecida como ukiyo-zô-shi. Um dos autores mais bem dotados é Saikaku Ihara, célebre pelas observações perspicazes sobre a realidade dos comerciantes. Mais ou menos na mesma época, difunde-se o hai-kai. Nesse mister, entre outros, destacou-se Bashô Matsuo pela sua visão tristonha entre o homem e a natureza. Devido a sua simplicidade, o hai-kai alcançou popularidade nas diversas camadas sociais. É igualmente dessa época a difusão do teatro das marionetes e do kabuki. Na pintura, apesar da evolução da tradicional Yamatoe, o que caracteriza essa fase histórica é, sem dúvida, o ukiyo-e. Este tinha como objetivo retratar os costumes do povo. Era uma arte de caráter popular impresso em xilogravura, portanto acessível a um grande número de pessoas. Inicialmente em preto e branco, posteriormente, o ukiyo-e é reproduzido em cores. Nela, pintores de talento como Utamaro Kitagawa, Sharaku Toshyusei, Hiroshige Utagawa, Hokusai Katsushika, retratavam as várias facetas dos habitantes das cidades. A própria arquitetura, afastando-se um pouco da construção de templos e palácios, começa a se preocupar com a praticidade e o conforto requerido pelos moradores urbanos. $\mathrm{O}$ que se deve salientar aqui é o fato da cultura engendrada no período Edo estar ligada a característica de uma grande parte da população nipônica, sobretudo a dos "burgueses" Ao longo de mais de duzentos anos, transforma-se numa tradição cultural, representando, naquilo que existe de melhor e do pior, a sociedade nipônica antes da Era Meiji.

III

No século XIX, o xogunato tinha os seus dias contados. Havia dois motivos principais para isso. $O$ primeiro era a contradição interna do próprio sistema. Baseado na economia agrícola, bakufu, no entanto, não concedera nenhum privilégio à mesma. Muito pelo contrário. Os lavradores foram deixados na mais abjeta miséria, no limite da sua subsistência. Por conseguinte, qualquer imprevisto, qualquer contratempo provocava o surgimento da mais negra fome, resultando em tragédia. Dessa forma, tornavam-se inevitáveis as rebeliōes, as insurreições, os levantes camponeses. De fato, estas ocorreram com inusitada freqüência na segunda metade do século XVIII. Porém, o xogunato pouco fez para melhorar a situação do campo.

$\mathrm{O}$ segundo motivo remete-se a conjuntura internacional. Após a Revolução Industrial na segunda metade do século XVIII, o capitalismo tornou-se industrial, apanágio da ideologia liberal. Em conseqüência, as potências industriais queriam abrir mercados no mundo todo. $O$ único continente ainda relativamente fechado à expansão de mercados era a Ásia. Com a produção em massa resultante da industrialização, o mercado consumidor tornava-se vital para o funcionamento do sistema capitalista. Sobretudo nos meados do século XIX, com a ascensão de novos países industriais como a França, Rússia, Alemanha e Estados Unidos, a competição econômica acirrou-se. A procura de novos mer- 
cados tornou-se vital para a sobrevivência, daí a investida ocidental em relação ao continente asiático. Era, portanto, uma questão de tempo a abertura dos portos da terra das cerejeiras.

De fato, em 1853, a armada norte-americana, comandada pelo comodoro Perry, apareceu com os seus temíveis "navios negros" no porto de Uraga, exigindo o fim do fechamento de portos. O bakufu de Tokugawa não teve forças para repeli-la, firmando no ano seguinte o acordo pelo qual abriu os portos de Shimoda e Hakodate. Essa demonstração de fraqueza do xogunato ascendeu o estopim da enorme insatisfação existente em todas as camadas sociais. Liderados pelos samurais de baixa hierarquia, depois de um longo processo insurrecional, foi instaurado a Restauração Meiji (1868). Abria-se o caminho para o Japão moderno.

A missão do governo Meiji era modernizar a nação. Isso significava a nível político o estabelecimento de um poder absolutista e a implantação de uma constituição; a nível econômico, a adoção do capitalismo e a captação de colônias e a nível cultural, a introdução da ciência e a sua aplicação na forma de tecnologia. Com admirável coerência e determinação de ferro, os heróis da Restauração cumpriram essa tarefa. Saliente-se que esses líderes, após várias missões nas quais observaram as características dos países ocidentais e o estado dos seus vizinhos asiáticos, optaram por uma linha de independência nacional, sem vínculo com qualquer potência da época. Obviamente, essa opção significou muitos sacrifícios e muita dor de cabeça. No início, foram novamente os agricultores os sacrificados. Sem uma indústria avançada ainda, a única fonte viável para financiar o desenvolvimento era exatamente a produção agrícola. Foi realizada uma reforma tributária para tornar mais eficiente a cobrança do imposto rural. O ônus da própria educação obrigatória recaiu sobre o bolso dos lavradores. Diante de tamanha opressão não é de se admirar que as rebeliōes camponesas continuassem freqüentes. De toda forma, as transformaçōes sócio-econômicas necessárias foram realizadas.

Nos primeiros anos da fase Meiji, no afã de libertar-se dos costumes medievais vigentes no período anterior, processou-se uma ocidentalização superficial e apressada. Tudo, ou quase tudo que era ocidental foi valorizado. Dessa forma abandonou-se os quimonos para utilizar roupas no estilo europeu, difundiu-se o uso de guarda-chuva, dos sapatos. Foram introduzidos alguns costumes da vida social do ocidente, tornando-se famoso os bailes da high-society nipônica nas dependências do célcbre Rokumei-kan. Como uma reação ao passado, desprezava-se tudo relacionado com a tradição cultural japonesa. Desse modo destruiu-se ou vendeu-se por preço de banana edifícios do passado e produções artísticas antigas. O próprio budismo sofreu ataques, sobremodo do xintoísmo interessado em tornar-se na religião oficial.

Entretanto, ao lado de uma ocidentalização de fachada, começou-se igualmente um trabalho sério de modernização compatível com uma nação desenvolvida. Para isso foi importante o papel desempenhado por pensadores iluministas como Yukichi Fukuzawa, Amane Nishi, Mamichi Tsuda e outros, di- 
vulgando não só as idéias ocidentais, mas também adaptadas à realidade japonesa, nas páginas, sobretudo, da revista Mei-Roku sha. Entre eles, um dos mais influentes parece ter sido Yukichi Fukuzawa. Ele dedicou sua vida para ajudar a acabar com os hábitos feudais profundamente enraizados nos seus patrícios, defendendo a implantação de um espírito de independência para poder moldar uma nação soberana. Condenou a proliferação de estudos inúteis e propagandeou a necessidade de cultivar outros mais práticos úteis para a saúde e obtenção de lucros. Foi também entusiasta da economia capitalista difundindo uma moral burguesa.

Nesse ambiente, foi introduzida a ciência moderna. Porém, mais do que pela preocupação cultural, ela provinha das necessidades militares. Dentro das coordenadas do imperialismo que começava a se delinear na segunda metade do século, uma nação para ser livre tinha de ser militarmente forte. Captando essa realidade, o governo Meiji promoveu o fortalecimento das suas forças armadas. No início, a própria industrialização era dirigida para fins militares. A implantação da indústria pesada como a siderúrgia, naval e outras se fez as expensas do Estado, com esses objetivos. Só mais tarde é que essas indústrias seriam privatizadas. Entretanto, os líderes do império nipônico sabiam que uma industrialização avançada só poderia ser alcançada tendo como base uma ciência moderna. Esta era essencial mesmo que a intenção maior fosse apenas a transferência de tecnologia. Afinal, estava-se adentrando a um período de fastígio da tecnologia entendida como aplicação da ciência para os problemas industriais.

Então é realizado um enorme esforço para o estabelecimento da ciência e do seu ensino. A Universidade de Tóquio, criada em 1869, torna-se uma instituição modelar nesse sentido, graças a contratação de numerosos professores estrangeiros. Logo começam a surgir talentos nativos que tornam desnecessários o auxílio dos mestres forâneos. Outras universidades imperiais vão sendo fundadas em outras localidades, ao lado de escolas superiores particulares como Keiô e Waseda. Rapidamente, surgiram alguns resultados científicos de valor, comprovando o bom nível alcançado pela ciência. Destarde, até o início do século XX, podem ser citados, por exemplo, os trabalhos de Shibazaburo Kitazato e Kiyoshi Shiga descobrindo os micróbios responsáveis pela desinteria, de Jokichi Takamine sobre a descoberta da adrenalina, de Hisashi Kimura sobre o "Termo z", de Hantaro Nagaoka pesquisando a estrutura atômica, de Kotaro Honda investigando aços especiais etc., além daqueles do internacional Hideyo Noguchi, particularmente sobre sífilis, nos laboratórios da Fundação Rockefeller.

Todavia, devido às suas características militares e à ênfase no seu lado prático, essa ciência desenvolvida pelos pesquisadores japoneses sofria constrangimentos de vários matizes. Um caso típico é o trabalho citado acima de Nagaoka. Este talentoso cientista propôs um modelo atômico muito semelhante ao de Rutherford em 1903, portanto, muito antes que o pesquisador inglês. Contudo, os maiorais da Academia de Ciências do Japão chamaram o jovem 
pesquisador e instaram para que ele não continuasse nessa direção porquanto segundo a douta opinião deles a investigação do átomo não seria do domínio da física, mas sim, da metafísica. Nagaoka acatou a imposição dos acadêmicos e a glória da descoberta da estrutura atômica ficou com Rutherford. Nesse sentido, a introdução da ciência significou modernização para a terra das cerejeiras, porém, não escapou da distorção resultante da militarização e do pragmatismo reinante na Restauração Meiji.

Por outro lado, no decorrer da modernização, alguns valores tradicionais foram resgatados. Ironicamente, um dos personagens fundamentais desse resgate no campo das artes plásticas é um estrangeiro. Trata-se do professor hispano-americano Fenollosa. Convidado para ensinar filosofia na Universidade de Tóquio, Fenollosa logo se tornou num admirador da arte japonesa. Em virtude de seus esforços, tornou-se possível a fundação da Escola de Artes de Tóquio. Juntamente com o seu discípulo Tenshin Okakura, esse professor americano ajudou os nipônicos a recuperarem o orgulho pela pintura do estilo japonês. Em conseqüência, uma plêiade de pintores, a começar por Hogai Kanô, Gahô Hashimoto, culminando com Kogyo Terasaki, Daikan Yokoyama, Kansan Shimomura e outros, desenvolveu uma atividade muito dinâmica, ressaltando a originalidade japonesa. Em alguns outros campos de cultura, ocorreu igualmente esse resgate da tradição, não obstante, dirigida para a modernidade.

As características da sociedade nipônica estão bem demarcadas na associação um tanto contraditória dessa modernidade representada pela ciência e tecnologia e desse tradicional configurado em alguns ramos da sua cultura artística. É nessa mistura aparentemente exótica que se deve procurar as razões do processo histórico vivido pelos japoneses até o término da Segunda Guerra Mundial. 